\title{
Aquaporin 3 Expression Is Up-Regulated by TGF- $\beta 1$ in Rat Peritoneal Mesothelial Cells and Plays a Role in Wound Healing
}

\author{
Hye-Myung Ryu, ${ }^{*}$ Eun-Joo Oh, ${ }^{*}$ Sun-Hee Park, ${ }^{*}$ \\ Chan-Duck Kim, ${ }^{*}$ Ji-Young Choi, ${ }^{*}$ Jang-Hee Cho, ${ }^{*}$ \\ In-San Kim, ${ }^{\dagger}$ Tae-Hwan Kwon, ${ }^{\dagger}$ \\ Ho-Young Chung, ${ }^{\ddagger}$ Min Yoo, ${ }^{\S}$ and Yong-Lim Kim*† \\ From the Division of Nephrology, ${ }^{*}$ Department of Internal Medicine, \\ the Department of Biochemistry and Cell and Matrix Research \\ Institute, ${ }^{\dagger}$ and the Department of Surgery, ${ }^{\ddagger}$ Kyungpook National \\ University School of Medicine, Daegu; and the Department of \\ Biology, Keimyung University, Daegu, South Korea
}

\begin{abstract}
Aquaporin 3 (AQP3) is expressed in many tissues including the peritoneum and kidney. In cultured mesothelial cells, glucose up-regulates AQP3, which may be important for water transport through the peritoneal membrane. However, there has been no research into the role of AQP3 in human peritoneal mesothelial cell (HPMC) migration or peritoneal fibrosis. We investigated the effects of transforming growth factor- $\beta 1$ (TGF- $\beta 1$ ) on AQP3 expression in HPMCs. We also investigated the role of AQP3 in the peritoneal wound healing process in rats. Chronic exposure to glucose-containing solution increased peritoneal myofibroblasts, with TGF- $\beta 1$ and AQP3 expression in a model of long-term peritoneal dialysis. In vitro, TGF- $\beta 1$ induced AQP3 expression in HPMCs. AQP3 knockdown by small-interfering RNA inhibited TGF- $\beta 1$-induced AQP3 and $\alpha$-smooth muscle actin expression and also slowed HPMC migration. AQP3 overexpression induced faster migration of HPMCs. Treatment with an extracellular signalregulated kinase inhibitor and p38 kinase inhibitor attenuated TGF- $\beta 1$-induced AQP3 expression in HPMCs. These data suggest that TGF- $\beta 1$ induces $A Q P 3$ and that $A Q P 3$ has a critical role in TGF- $\beta$-induced HPMC migration. These findings provide evidence of a novel role for AQP3 in peritoneal fibrosis and wound healing. The effect of TGF- $\beta 1$ on AQP3 expression in HPMCs is mediated, at least in part, by ERK and $\mathrm{p} 38$ signaling. (Am J Pathol 2012, 181: 2047-2057; bttp://dx.doi.org/10.1016/j.ajpath.2012.08.018)
\end{abstract}

The aquaporins (AQPs) are a family of small integral membrane proteins that transport water alone or water plus small solutes such as glycerol. ${ }^{1}$ To date, 13 subtypes of AQPs have been identified in mammals. ${ }^{2,3}$ AQP3 is permeable not only to water but also to glycerol and is thus sometimes called "aquaglyceroporin." $A Q P 3$ is expressed specifically in skin keratinocytes, in epithelial cells in the airway, and in the collecting ducts of the kidneys. ${ }^{4}$

Recent research has found that AQPs contribute to cell migration in endothelial cells, ${ }^{5}$ brain astroglial cells, ${ }^{6}$ and kidney proximal tubule cells. ${ }^{7}$ In cultured mesothelial cells, glucose up-regulates both mRNA and protein expression of AQP1 and AQP3, which may be important for water transport through the peritoneal membrane. ${ }^{8,9}$ However, there has been no research into the role of AQP3 in human peritoneal mesothelial cell (HPMC) migration or peritoneal fibrosis.

Peritoneal injury, whether induced by infection, ischemia, inflammation, or surgery, can lead to peritoneal adhesions and fibrosis. Transforming growth factor- $\beta$ (TGF- $\beta$ ) is a primary regulator of this process. ${ }^{10}$ To investigate the role of AQP3 in a model of animal peritoneal injury, we used the long-term peritoneal dialysis (PD) model. Long-term exposure to PD fluids results in peritoneal injury, with concurrent structural changes and functional decline such as ultrafiltration loss. ${ }^{11}$ Peritoneal dialysis fluids are hyperosmotic solutions that are usually glucose based. High glucose concentrations and glucose degradation products from PD solutions lead to production of TGF- $\beta$ and vascular endothelial growth factor by mesothelial cells. ${ }^{12}$ The peritoneum is the largest extensive serous membrane in the body, covering the

Supported by a grant from the Korean National Research Foundation (20110019443); Kyungpook National University Research Fund, 2012; and the Korean Healthcare Technology R\&D Project (A111345 and A102065), Ministry of Health and Welfare, Republic of Korea.

Accepted for publication August 13, 2012.

Supplemental material for this article can be found at $h t t p: / / a j p$. amjpathol.org or at $h$ ttp://dx.doi.org/10.1016/j.ajpath.2012.08.018.

Address reprint requests to Yong-Lim Kim, M.D., Division of Nephrology, Department of Internal Medicine, Kyungpook National University Hospital, 50 Samduk-dong 2 Ga, Jung-gu, Daegu 700-721, South Korea. E-mail: ylkim@knu.ac.kr. 
visceral organs and lining the abdominal cavity. The peritoneum comprises a monolayer of mesothelial cells that provide the first line of defense in peritoneal protection during chemical, surgical, or bacterial insult. ${ }^{13}$

Pathologic changes in the peritoneal membrane due to long-term PD are characterized by loss of mesothelial cells and enlargement of the submesothelial compact zone due to interstitial fibrosis. ${ }^{14}$ Myofibroblasts in peritoneal tissue are $\alpha$-smooth muscle actin ( $\alpha$-SMA)-positive interstitial cells. ${ }^{15}$ Fibrosis is a disease process common to the kidney and lungs in the context of reiterative injury or infection, ${ }^{16}$ and cell transdifferentiation is a generic process by which myofibroblasts are generated in injured tissues such as the kidney and lung. ${ }^{17,18}$ Myofibroblasts are key cells in the wound-healing response and are responsible for wound contraction, recruitment of inflammatory cells, and remodeling of the extracellular matrix. ${ }^{16}$

TGF- $\beta$, a member of a family of growth factors that are important in wound healing and response to injury, ${ }^{19,20}$ is also a key fibrogenic growth factor in the peritoneum and mediates peritoneal fibrosis. TGF- $\beta$ stimulates fibroblast proliferation and increases the synthesis of a number of extracellular matrix components. Although transient TGF- $\beta 1$ activity is involved in the repair and regeneration of tissues, persistent TGF- $\beta 1$ function leads to excessive fibrosis. ${ }^{21}$ However, the relationship between TGF- $\beta 1$ and AQP3 is not known.

The objectives of the present study were to investigate the effects of TGF- $\beta 1$ on AQP3 expression in HPMCs and the role of AQP3 both in vitro and in vivo in the wound healing process and fibrosis.

\section{Materials and Methods}

\section{Animal Model of PD}

The rat PD model, which is a long-term infusion model, was used to investigate the role of AQP3 in peritoneal injury. In brief, permanent PD catheters were inserted in 18 male 8-week-old Sprague-Dawley rats (Hyochang Science, Daegu, Korea) that were divided into 2 groups: the control group $(\mathrm{C})$, in which each rat had a catheter but received no dialysis solution infusion, and the dialysis group (D), in which each rat had a catheter and received dialysis solution infusion for 8 weeks. Group D rats received infusions of $25 \mathrm{~mL} 4.25 \%$ glucose dialysis solution (Dianeal; Baxter Healthcare Ltd., Singapore) b.i.d. for 8 weeks. ${ }^{22}$ At the end of the 8 weeks, all rats were sacrificed, and peritoneal tissue was collected. AQP3 and $\alpha$-SMA expression in peritoneal tissue was analyzed using Western blot analysis. All experiments were performed according to animal experimental procedures approved by the Animal Care and Use Committee of Kyungpook National University.

\section{Immunofluorescence of Peritoneum}

Immunofluorescence was performed as described previously. 22 Primary antibodies against pan-cytokeratin (Thermo Fisher Scientific, Inc., Fremont, CA), $\alpha$-SMA (Ab- cam PLC, Cambridge, UK), TGF- $\beta 1$ (Santa Cruz Biotechnology, Inc., Santa Cruz, CA), and AQP3 (Alomone Laboratories, Ltd., Jerusalem, Israel) were used.

\section{Cell Culture and TGF- $\beta 1$ Treatment}

HPMCs were collected from omental tissue from patients undergoing abdominal surgery. Informed consent was provided by each patient. HPMCs were isolated using the trypsin-EDTA method and cultured in M199 medium containing 20\% fetal bovine serum (FBS). To confirm the HPMC population before starting experiments, we usually tested the HPMC population via immunofluorescence staining of cytokeratin and $\alpha$-SMA. To minimize the fibroblast contamination, we used a cobblestone-shaped HPMC, and if the fibroblastoid-shaped cell was contained above $5 \%$, we discarded the cell. The cells were plated at confluence and allowed to rest in 1\% FBScontaining M199 medium for 24 hours to allow growth synchronization. The cells were then exposed to recombinant human TGF- $\beta 1$ (R\&D Systems, Inc., Minneapolis, $\mathrm{MN}$ ) at concentrations of $2 \mathrm{ng} / \mathrm{mL}$ for 48 hours. For dosedependent studies, TGF- $\beta 1$ was used at 1, 2, 3, 4, and 5 $\mathrm{ng} / \mathrm{mL}$. For time-dependent studies, HPMCs were treated for 24,48 , and 72 hours with 2 ng/mL TGF- $\beta 1$. For phosphorylation studies, HPMCs were treated for 1 hour with 2 $\mathrm{ng} / \mathrm{mL}$ TGF- $\beta 1$.

\section{Western Blot Analysis}

Western blot analysis was performed as described previously, ${ }^{23}$ using primary antibodies against $\alpha$-SMA (Sigma-Aldrich, St. Louis, MO), AQP3 (Alomone Laboratories), $\quad \beta$-actin (Sigma-Aldrich), ERK (Santa Cruz Biotechnology), phosphorylated (p) ERK, p38, p-p38, cJun N-terminal kinase (JNK), and p-JNK (Cell Signaling Technology, Inc., Beverly, MA). A horseradish-peroxidase-conjugated polyclonal goat anti-rabbit immunoglobulin or goat anti-mouse immunoglobulin (Dako, Glostrup, Denmark) were used as secondary antibodies for Western blot analysis. Positive immunoreactive bands were quantified via densitometry and compared with human $\beta$-actin expression.

\section{Real-Time RT-PCR}

Real-time RT-PCR was performed as described previously. ${ }^{23}$ The sequences of the primer pairs were as follows: AQP3, forward 5'-GACC TाTGCCATGTGCTTCCT-3' and reverse 5'-CCAAAAACTATTCCAGCACCCA-3'; $\beta$-actin, forward 5'-CTGTCCACCTTCCAGCAGATGT-3' and reverse 5'-CGCAACTAAGTCATAGTCCGCC-3'; and $\alpha$-SMA, forward 5'-TCCGGAGCGCAAATACTCTGT-3' and reverse 5'-CCGGCTTCATCGTATTCCTGT-3'.

\section{Transfection of HPMCs with AQP3 siRNA}

Human AQP3 small-interfering RNA (siRNA) and nontargeting siRNA as a negative control were purchased from Dharmacon, Inc. (Chicago, IL) and used at $20 \mathrm{nmol} / \mathrm{L}$. 
Opti-MEM transfection media and lipofectamine (both from Invitrogen, Paisley, UK) were used for transfection. HPMCs were seeded at 1 day before transfection and cultured so that they were $40 \%$ to $50 \%$ confluent on the following day. RNA interference (RNAi) duplexes for AQP3 were mixed with lipofectamine to form a transfection complex that was added to cells in 6-well plates. At 24 hours after knockdown of AQP3, cells were incubated in M199 medium containing 1\% FBS for 24 hours and then with or without $2 \mathrm{ng} / \mathrm{mL}$ TGF- $\beta 1$ for 48 hours. Realtime RT-PCR, Western blot analysis, and immunofluorescence were performed to analyze AQP3 and $\alpha$-SMA expression.

\section{Proliferation Assay}

Proliferation was measured via 5-bromo-2-deoxyuridine (BrdU) incorporation. Cells were plated in 96-well plates at $1 \times 10^{4}$ cells per well. After 24 hours of siRNA transfection, cells were incubated in M199 medium containing $1 \%$ FBS for 24 hours and then were treated with $2 \mathrm{ng} / \mathrm{mL}$ TGF- $\beta 1$ for 24 hours. BrdU labeling solution was added, and cells were reincubated for an additional 24 hours. Incorporated BrdU was detected by using a BrdU ELISA kit (Calbiochem Corp., La Jolla, CA) according to the manufacturer's instructions.

\section{Construction of a Recombinant Adenovirus Human AQP3 Gene}

Adenoviral transfection of the human AQP3 gene was used to investigate the effect of AQP3 on HPMCs. In brief, human AQP3 CDNA was purchased from Origene Technologies, Inc. (Rockville, MD), and AQP3 cDNA was cloned into the pGEM-T Easy Vector (Promega Corp., Madison, WI). Restriction enzyme analyses and DNA sequencing were used to confirm the accuracy of the pGEM-T-AQP3 sequence. AQP3 cDNA from pGEM-TAQP3 was inserted into the pShuttle-CMV vector. pShuttle/AQP3 plasmids were linearized with restriction enzymes and co-transformed into Escherichia coli by using pAdEasy-1 vector. Recombinant plasmids were transfected into the adenovirus packing cell line HEK293. Green fluorescent protein adenovirus (Ad-GFP) (Seoulin Corp., Seoul, Korea) was used as a negative control.

\section{Adenoviral Transduction}

HPMCs were infected with AQP3 (Ad-AQP3) and Ad-GFP at a concentration of 100 multiplicity of infection (MOI) for 24 hours. After transfection, the cells were incubated in M199 medium containing 1\% FBS for 24 hours, then further incubated with or without $2 \mathrm{ng} / \mathrm{mL}$ TGF- $\beta 1$ for 48 hours. Real-time RT-PCR, Western blot analysis, and immunofluorescence were performed to analyze AQP3 and $\alpha$-SMA expression.

\section{Immunofluorescence of HPMCs}

Immunofluorescence was performed as described previously. ${ }^{23}$ For immunofluorescence staining, primary antibodies against $\alpha$-SMA (Sigma-Aldrich), pan-cytokeratin (Thermo Fisher Scientific), and AQP3 (Alomone Laboratories) were used. Fluorescein-conjugated secondary antibodies (AlexaFluor 488 and AlexaFluor 594; InvitrogenMolecular Probes, Inc., Eugene, OR) were used for immunofluorescence staining. The nuclei were counterstained with DAPI, and the slides were mounted with anti-fade mounting reagent (Invitrogen-Molecular Probes). The slides were viewed using a Zeiss confocal scanning laser microscope using the LSM 5 EXCITER (Carl Zeiss AG, Oberkochen, Germany).

We used the mouse anti- $\alpha$-SMA (Sigma-Aldrich) for Western blot analysis and immunofluorescence staining in in vitro experiments. In in vivo experiments, for double immunofluorescence staining with mouse anti-pan-cytokeratin (Thermo Fisher Scientific), we used rabbit anti- $\alpha$ SMA (Abcam).

\section{Phalloidin Staining}

Cells were plated onto Labtek slides in M199 medium plus 20\% FBS. Cells were washed with PBS and fixed with $3.7 \%$ paraformaldehyde for 30 minutes at room temperature. The cells were incubated with Alexa594-phalloidin (Invitrogen-Molecular Probes) diluted in 1\% bovine serum albumin-PBS at a final concentration of $5 \mathrm{U} / \mathrm{mL}$ for 30 minutes. Cells were counterstained with DAPI.

\section{Scratch Wound-Healing Assay}

HPMCs in 6-well plates were wounded by means of manual scraping with a yellow pipette tip. Plates were washed twice to remove nonadherent cells and were incubated with serum-free M199 medium for 24 hours. The cells were then transfected with siAQP3 or adenovirus-mediated AQP3 for 24 hours. After transfection, the cells were treated with $10 \mu \mathrm{g} / \mathrm{mL}$ mitomycin $\mathrm{C}$ for 1 hour before the scratch to block proliferation. Then the cells were incubated with recombinant human TGF- $\beta 1$ at $2 \mathrm{ng} / \mathrm{mL}$, and digital images were obtained at 0,12 , and 24 hours.

Healing was assessed on 5 parts of the scratch at each time point using the Internet-based software Image $J$ to compare wound width with that at time 0 . At least 5 regions of wound closure on each scratch were measured in 3 separate experiments, and the results were analyzed statistically.

\section{Matrigel Invasion Assay}

The matrigel invasion assay was performed to assess the effects of AQP3 on the migration of TGF- $\beta 1$-treated HPMCs. Transwell inserts (12-wells, polycarbonate, 8- $\mu \mathrm{m}$ pore size) from Corning, Inc. (Corning, NY) were coated with $200 \mu \mathrm{L}$ matrigel (final concentration, $1.0 \mathrm{mg} / \mathrm{mL}$ in ice-cold serum-free medium) (BD Biosciences, San Jose, CA) and allowed to dry at $37^{\circ} \mathrm{C}$ for 3 hours. Growth medium (10\% FBS containing $5 \mu \mathrm{g} / \mathrm{mL}$ fibronectin) was 
added to the lower wells of the chambers. At 24 hours after transfection, cells were washed twice with serumfree medium and trypsinized, and $200 \mu \mathrm{L}$ cell suspension $\left(1 \times 10^{5}\right.$ cells $)$ from each sample was added to each well. After 24 hours of incubation at $37^{\circ} \mathrm{C}$, the cells on the top surface of the chamber were gently removed using cotton swabs. Migrated cells remaining on the bottom surface were stained with Diff-Quik (Fisher Scientific, Pittsburgh, PA) or $0.1 \%$ crystal violet (Sigma-Aldrich). The number of cells that had migrated to the lower side of the filter was counted under a light microscope at $\times 200$ magnification in 5 randomly selected fields.

\section{Effect of MAPK Inhibitors on TGF- $\beta 1-$ Induced AQP3 Expression}

HPMCs were treated for 1 hour with $20 \mu \mathrm{mol} / \mathrm{L}$ of either PD98059, SB203580, or SP600125, which are specific chemical inhibitors of ERK, p38, or JNK, respectively. Subsequently, $2 \mathrm{ng} / \mathrm{mL}$ TGF- $\beta 1$ was added, and the cells were incubated for 48 hours. The level of AQP3 protein expression after treatment with mitogen-activated protein kinase (MAPK) inhibitor was assessed using Western blotting.

\section{Statistical Analysis}

The $t$-test was used for comparisons where indicated. The results are expressed as mean \pm SEM. $P<0.05$ was considered significant. Statistical analyses were performed using SigmaPlot software (version 11.0; Systat Software, Inc., San Jose, CA).

\section{Results}

\section{Chronic Exposure to Glucose-Containing} Solution Increases Peritoneal Myofibroblasts and AQP3 Expression in a Model of Chronic PD

We first used the rat model of chronic PD to investigate the role of AQP3 in peritoneal injury and fibrosis. Group $C$ rats had a catheter without infusion of dialysis solution, and group $D$ rats had a catheter with infusion of dialysis solution for 8 weeks. After 8 weeks of experimental PD, the peritoneal thickness of the abdominal wall in group $D$ rats was thicker than in group $\mathrm{C}$ rats, and increased vascularity was noted in group D rats (data not shown). Also at 8 weeks, the number of dual-stained cytokeratin- and $\alpha$-SMA-positive myofibroblasts in the submesothelial layer in group $D$ rats had increased, compared with those in group $\mathrm{C}$ rats, which was associated with decreased cytokeratin and increased $\alpha$-SMA expression (Figure 1A). There was strong TGF- $\beta 1$ expression in the thickened submesothelial matrix of the parietal peritoneum in group $D$ rats (Figure 1B).

AQP3 was detected in the peritoneal mesothelial layer in group $C$ rats and in the thickened submesothelial matrix of the parietal peritoneum in group $\mathrm{D}$ rats (Figure 1B). Western blot analysis revealed that AQP3 and $\alpha$-SMA protein expression was significantly higher in the abdominal walls of group $D$ rats than in group $C$ rats $(P<0.05)$ (Figure $1 C$ ).
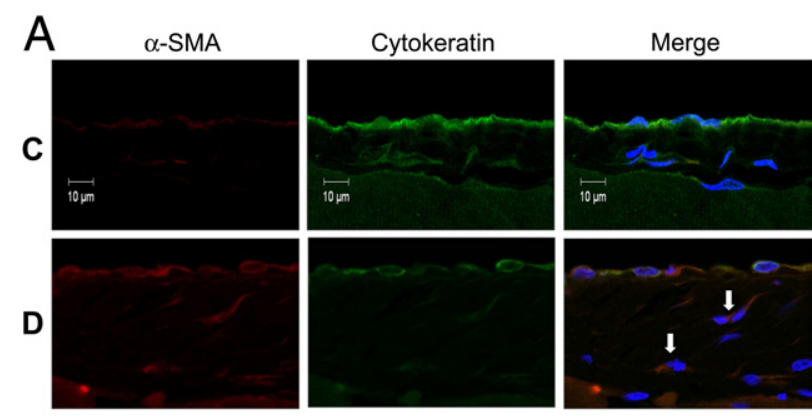

B
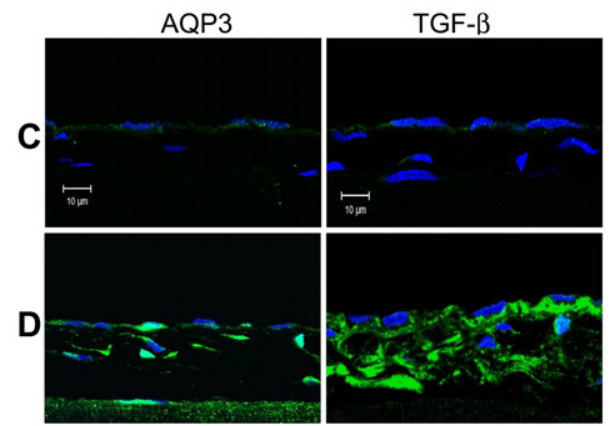

C

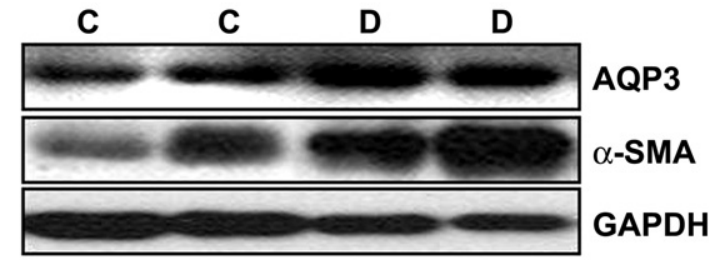

AQP3

$\alpha-S M A$
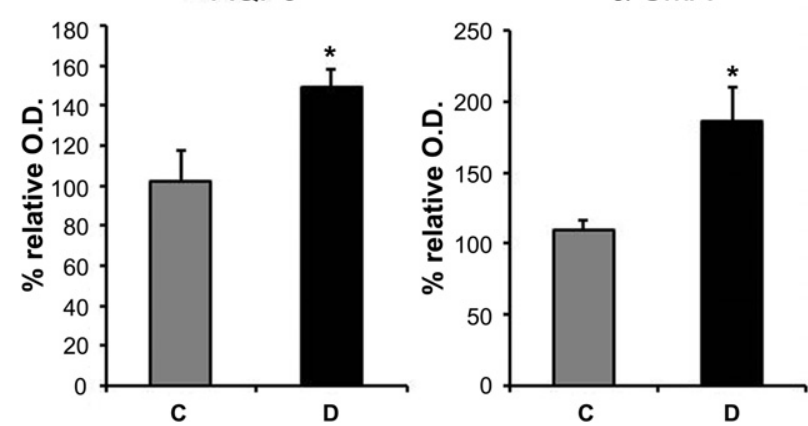

Figure 1. Expression of fibrosis markers and $A Q P 3$ after peritoneal injury. For the peritoneal dialysis experiments, rats were divided into 2 groups, a control group (C, $n=9)$ and a dialysis group (D, $n=9)$. After 8 weeks, the rats were sacrificed, and the peritoneal tissue was analyzed. A: Immunofluorescence staining for cytokeratin (green) and $\alpha$-smooth muscle actin ( $\alpha$ SMA; red) with nuclear counterstaining (DAPI; blue). Dual-stained cytokeratin- and $\alpha$-SMA-positive myofibroblasts are indicated by arrows. B Immunofluorescence staining for $\mathrm{AQP} 3$ and TGF- $\beta 1$ in rat parietal peritoneum. C: Immunoblotting of AQP3 and $\alpha$-SMA in the parietal peritoneum. ${ }^{*} P<0.05$ versus control

\section{TGF- $\beta 1$ Induces AQP3 and $\alpha$-SMA Expression in HPMCs}

To confirm the HPMC population, we tested it by using immunofluorescence staining of cytokeratin and $\alpha$-SMA. At confocal microscopy, cytokeratin was expressed in the great majority of confluent cells, whereas $\alpha$-SMApositive cells were rare (see Supplemental Figure S1 at http://ajp.amjpathol.org). To investigate the relationship of 
A
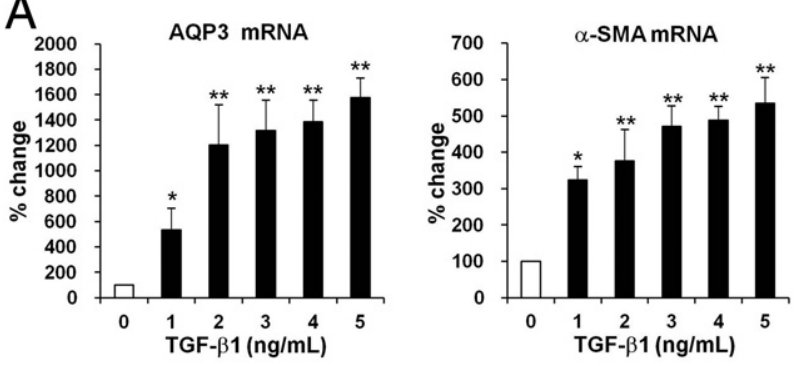

B
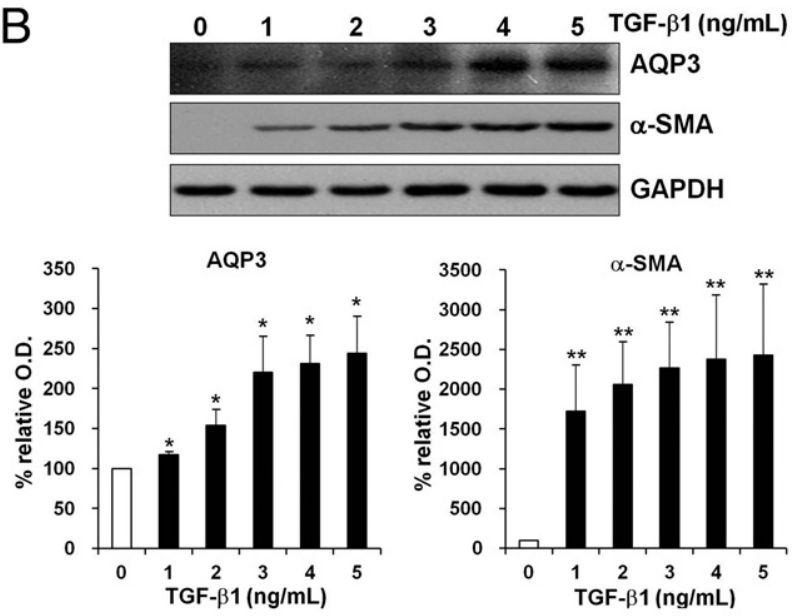

C
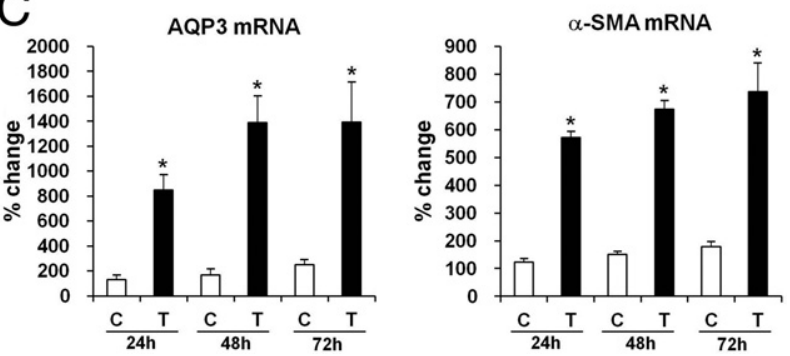

Figure 2. TGF- $\beta 1$ dose- and time-dependent changes in AQP 3 and $\alpha$-SMA expression in human peritoneal mesothelial cells (HPMCs). A and B: Cells were incubated with TGF- $\beta 1$ ( 1 to $5 \mathrm{ng} / \mathrm{mL}$, as indicated) for 48 hours. AQP3 and $\alpha$-SMA mRNA (A) and protein levels $(\mathbf{B})$ were assessed using real-time RT-PCR $(\mathbf{A})$ and Western blot analysis $(\mathbf{B})(n=4)$. C: HPMCs were treated with $2 \mathrm{ng} / \mathrm{mL}$ TGF- $\beta 1$ for 24,48 , and 72 hours. AQP3 and $\alpha$-SMA mRNA levels were measured using real-time RT-PCR $(n=4) .{ }^{*} P<0.05$ and ${ }^{* *} P<$ 0.01 versus control. C, control cells; T, treated cells.

AQP3 and TGF- $\beta 1$ in HPMCs, HPMCs were incubated in medium containing 1 to $5 \mathrm{ng} / \mathrm{mL}$ TGF- $\beta 1$ for 48 hours or were treated with $2 \mathrm{ng} / \mathrm{mL}$ TGF- $\beta 1$ for 24,48 , and 72 hours. Protein and mRNA expression levels of $\alpha$-SMA, a mesenchymal marker, and AQP3 were significantly upregulated after TGF- $\beta 1$ treatment. Specifically, TGF- $\beta 1$ induced $\alpha$-SMA and AQP3 expression in a dose- and time-dependent manner (Figure 2).

\section{AQP3 Knockdown Inhibits TGF- $\beta 1$-Induced $A Q P 3$ and $\alpha$-SMA Expression in HPMCs}

RNAi experiments were performed to further examine the role of AQP3 in TGF- $\beta 1$-treated HPMCs. Human AQP3 siRNA (siAQP3; $20 \mathrm{nmol} / \mathrm{L}$ ) or nontargeting siRNA ( $\mathrm{SiN}$;
$20 \mathrm{nmol} / \mathrm{L})$ were transfected into HPMCs. At 24 hours after siAQP3 or siN transfection, HPMCs were treated with $2 \mathrm{ng} / \mathrm{mL}$ TGF- $\beta 1$ or were left untreated for 48 hours, and AQP3 mRNA and protein expression were determined by means of real-time RT-PCR and Western blot analysis, respectively. Transfection with siAQP3 decreased AQP3 mRNA expression by $80 \%$ compared with control $(P<0.05)$ (Figure 3A) and also inhibited AQP3 protein expression compared with control $(P<0.05)$ (Figure 3B). Furthermore, TGF- $\beta 1$-induced AQP3 mRNA and protein expression levels in HPMCs were attenuated by siAQP3 transfection (Figure 3, A and B). Immunofluorescence staining demonstrated that the AQP3 signals were lower in siAQP3-transfected cells and were attenu-
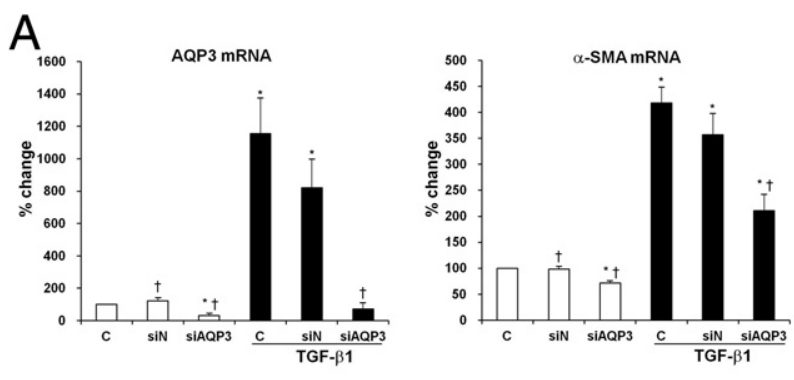

B
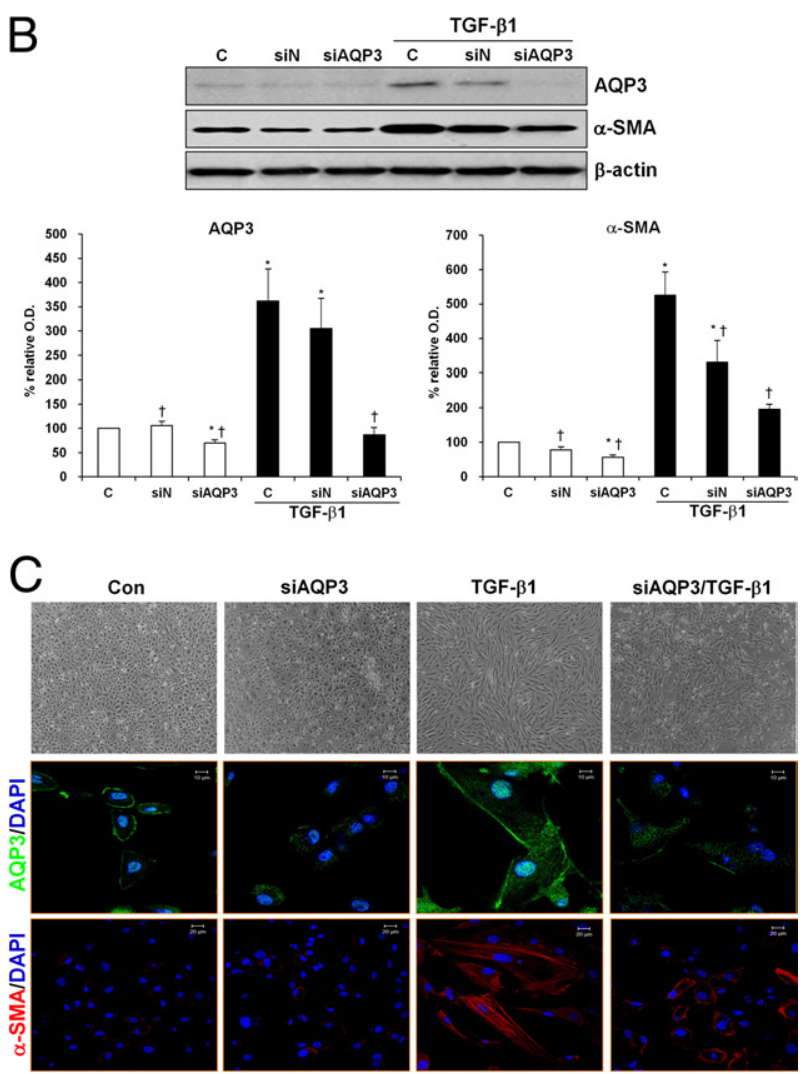

Figure 3. $A O P 3$ knockdown reduces TGF- $\beta 1$-induced AQP 3 and $\alpha$-SMA expression. HPMCs were transfected with AQP3-siRNA (siAQP3) or nontargeting-siRNA ( $\mathrm{siN}$ ) for 24 hours and then treated with $2 \mathrm{ng} / \mathrm{mL}$ TGF- $\beta 1$ for 48 hours. AQP 3 and $\alpha$-SMA expression was analyzed in cell lysates via real-time RT-PCR for mRNA $(n=4)(\mathbf{A})$ or Western blot analysis for proteins $(n=4)$ (B). ${ }^{*} P<0.05$ versus control; ${ }^{t} P<0.05$ versus TGF- $\beta 1$ control (C). C: Light micrographs (original magnification $\times 40$ ) and immunostaining of HPMCs for AQP3 (green) and $\alpha$-SMA (red) with nuclear counterstaining (DAPI; blue). Con, control 
ated in SiAQP3- or TGF- $\beta 1$-treated cells compared with the appropriate control cells. The morphologic changes induced by TGF- $\beta 1$ treatment were substantially reduced after siAQP3 transfection. In particular, the cobblestonelike appearance of TGF- $\beta 1$ - or siAQP3-treated cells remained unchanged (Figure $3 C$ ).

We also performed real-time RT-PCR, Western blot analysis, and indirect immunofluorescence staining to investigate changes in $\alpha$-SMA expression after siAQP3 transfection. Expression of $\alpha$-SMA protein and mRNA was significantly decreased compared with the control after siAQP3 transfection $(P<0.05)$ (Figure 3, A and B). Expression of $\alpha$-SMA was undetectable at immunofluorescence in untreated HPMCs but was strongly expressed in TGF- $\beta 1$-treated HPMCs. Furthermore, expression of $\alpha$-SMA was diminished in HPMCs transfected with SiAQP3 and treated with TGF- $\beta 1$ compared with cells treated only with TGF- $\beta 1$ (Figure 3 C).

\section{AQP3 Knockdown Inhibits TGF- $\beta 1$-Induced Cell Migration in HPMCs}

To investigate the role of AQP3 in HPMC migration, we used a wound-healing assay and a transwell migration assay to investigate HPMCs transfected with siAQP3. HPMCs were treated with mitomycin $\mathrm{C}$ for 1 hour before the scratch to prevent proliferation. In the in vitro wound-healing assay, wound closure was analyzed after cells were scraped from a confluent cell monolayer. TGF- $\beta 1$ accelerated wound closure, whereas siAQP3 inhibited TGF- $\beta 1$-induced HPMC motility, and as a result, the wound remained open (Figure 4A). Matrigel invasion assays demonstrated remarkable reductions in the invasive properties of HPMCs after treatment with siAQP3. The staining of cells that had migrated through the polycarbonate membrane demonstrated that the number of invasive cells was significantly reduced in HPMCs treated with siAQP3 or TGF- $\beta 1$ compared with TGF- $\beta 1$ alone (Figure 4B).

\section{Effect of TGF- $\beta 1$ and siAQP3 on Proliferation of HPMCs}

To verify whether wound closure in HPMCs is due to TGF- $\beta 1$-induced proliferation or TGF- $\beta 1$-induced migration, we performed BrdU incorporation assays (Figure $4 C)$. BrdU incorporation in these cells was inhibited by TGF- $\beta 1$ and was not changed by siAQP3 (Figure 4C).

\section{AQP3 Overexpression Increases $\alpha$-SMA in HPMCs}

To determine and optimize the adenoviral infection efficiency in mesothelial cells, we infected HPMCs with AdAQP3 at various MOIs for 24 hours. AQP3 mRNA and $\alpha$-SMA mRNA were significantly increased with increasing Ad-AQP3 in a dose-dependent manner (Figure 5A). Ad-AQP3-transfected HPMCs exhibited more prominent immunofluorescence staining of AQP3 than did control cells (Figure 5B).

To investigate the effects of AQP3 overexpression, HPMCs were infected with $100 \mathrm{MOls}$ of either Ad-GFP or
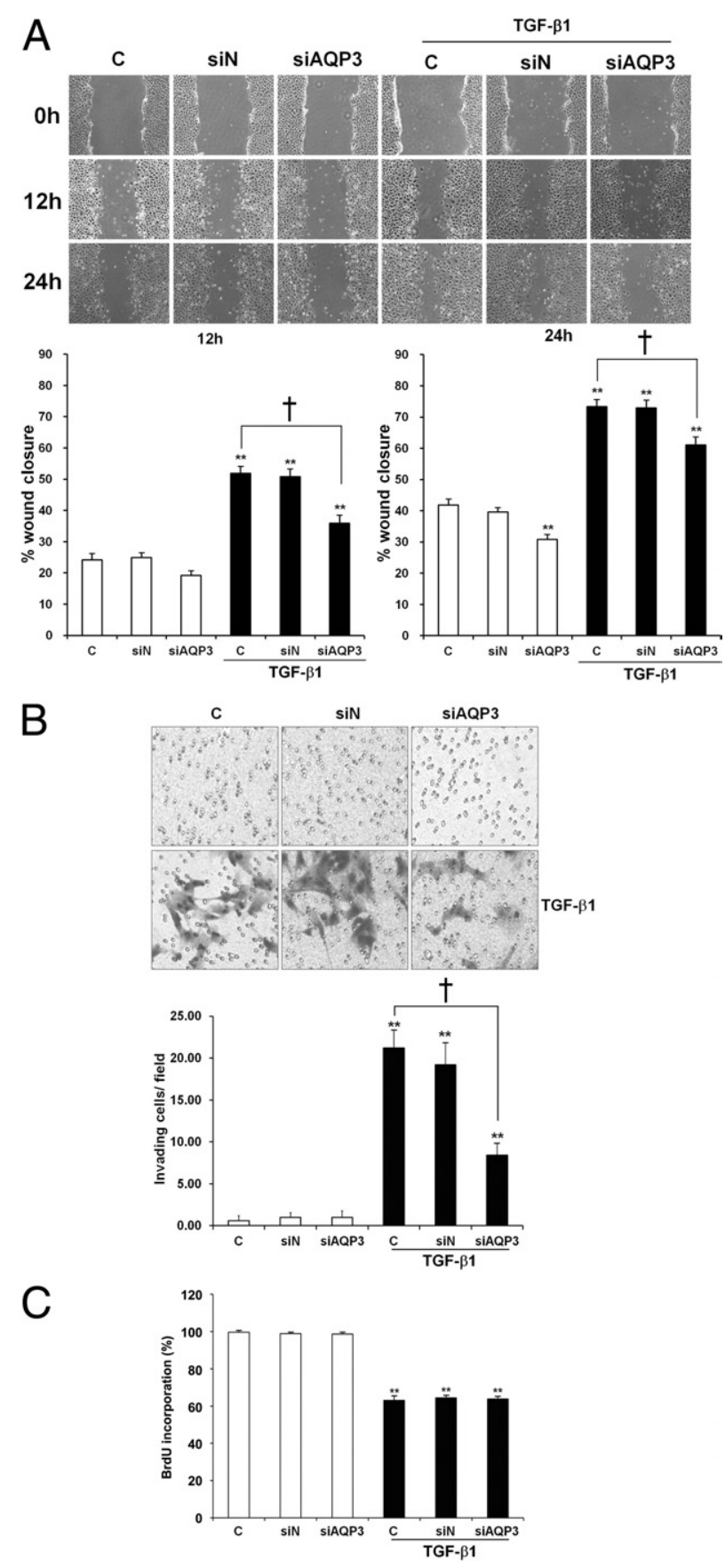

Figure 4. $A Q P 3$ knockdown slows HPMCs. A: In vitro wound-healing assay Light micrographs of wounded cell monolayers showed impaired wound closure at 12 and 24 hours after $A Q P 3$ siRNA (siAQP3) and nontargeting siRNA (siN) transfection with or without treatment with $2 \mathrm{ng} / \mathrm{mL}$ TGF- $\beta 1$. HPMCs were treated with $10 \mu \mathrm{g} / \mathrm{mL}$ mitomycin $\mathrm{C}$ for 1 hour before the scratch to block proliferation. B: Matrigel invasion assay. Invading cells were stained with DiffQuik solution. Data represent the mean \pm SEM number of cells in 5 randomly selected microscopic fields. Original magnification $\times 100$. C: BrdU cell proliferation assay. HPMCs were transfected with $A O P 3$-siRNA or siN for 24 hours and then treated with $2 \mathrm{ng} / \mathrm{mL}$ TGF- $\beta 1$ for 24 hours. BrdU labeling solutions were added, and cells were reincubated for an additional 24 hours. ${ }^{*} P<0.05$ and ${ }^{* *} P$ $<0.01$ versus control. ${ }^{\dagger} P<0.01$ versus TGF- $\beta 1$ control. C, control.

Ad-AQP3 for 24 hours, after which the cells were incubated with $2 \mathrm{ng} / \mathrm{mL}$ TGF- $\beta 1$ or were left untreated for 48 hours. AQP3 mRNA and protein were significantly increased after transfection of Ad-AQP3 compared with 
A
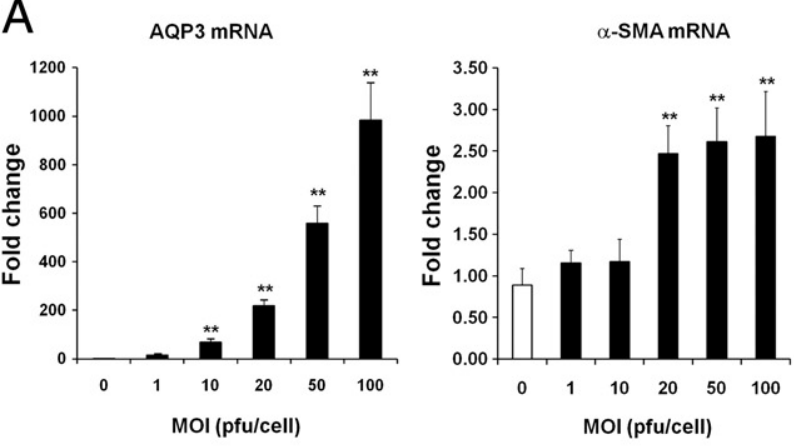

C

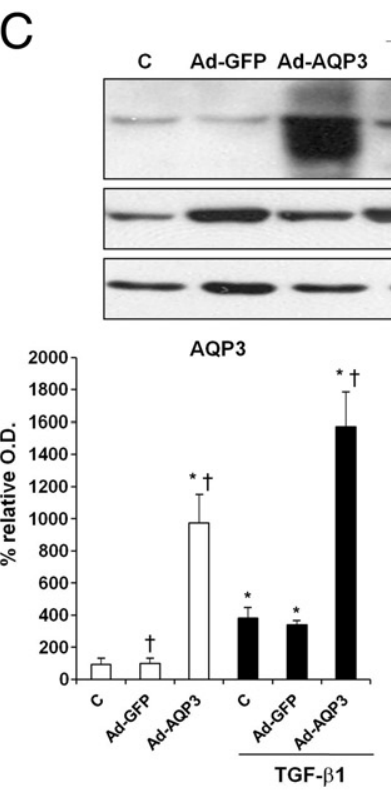

TGF- $\beta 1$

C Ad-GFP Ad-AQP3

E
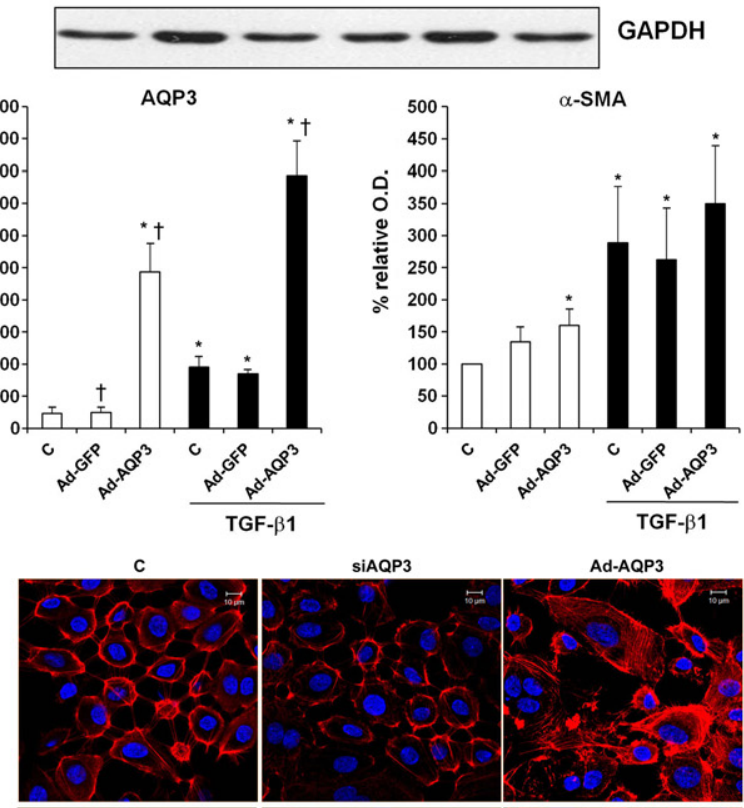

GAPDH

AQP3

$\alpha$-SMA
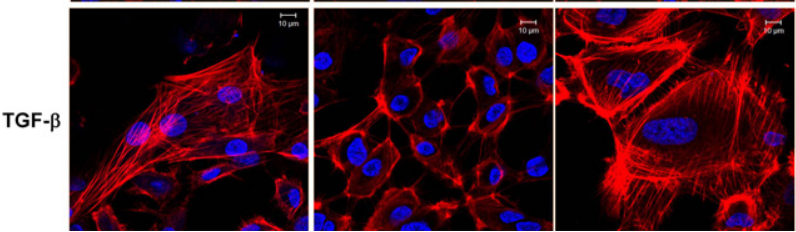

control $(P<0.05)$ (Figure 5). TGF- $\beta 1$-treated cells exhibited a greater increase in AQP3 protein expression; however, the AQP3 mRNA level was not significantly different in cells transfected with Ad-AQP3 compared with cells subjected to Ad-AQP3 transfection plus TGF- $\beta 1$ treatment. AQP3 overexpression increased $\alpha$-SMA protein and mRNA expression (Figure 5, C and D).

To examine the consequences of AQP3 expression on stress fiber formation, cells infected with siAQP3 or AdAQP3 were stained with phalloidin-Alexa594 conjugate. At phalloidin staining, TGF- $\beta 1$ stimulated reorganization of Factin filaments from an apical ringlike structure to stress

B

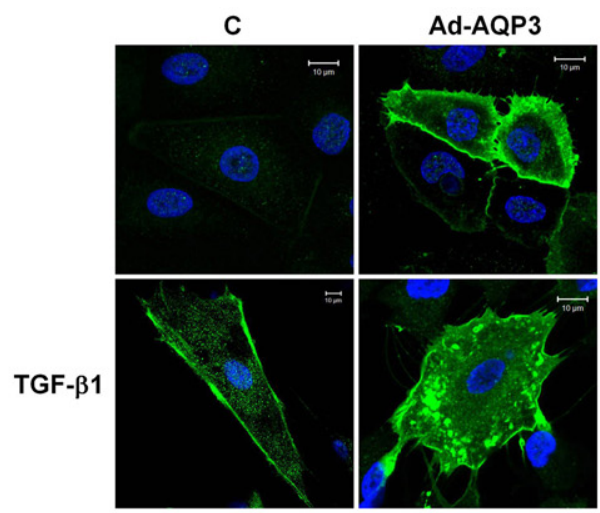

D
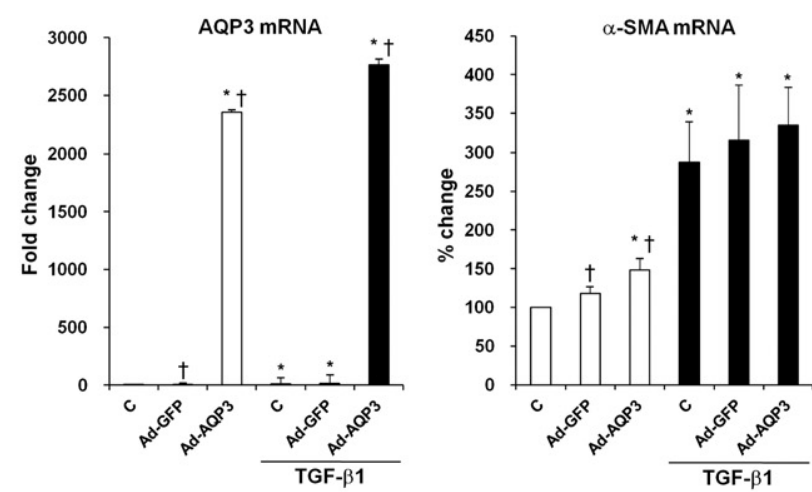

Figure 5. $A Q P 3$ overexpression induces AQP3 and $\alpha$-SMA. A: Expression of AQP3 and $\alpha$-SMA mRNA after adenoviral gene transfer of $A Q P 3$. HPMCs were infected with a recombinant adenovirus expressing $A Q P 3$ (Ad- $A Q P 3$ ) at increasing MOI values. AQP 3 and $\alpha$-SMA mRNA levels were quantitated using real-time RT-PCR $(n=4)$. B: Immunostaining of AQP3 (green) in HPMCs. HPMCs were infected with Ad-AQP3 (MOI $=100)$ for 24 hours and then treated with $2 \mathrm{ng} / \mathrm{mL}$ TGF- $\beta 1$ for 48 hours. Scale bar $=10 \mu \mathrm{m}$. C: Immunoblotting for AQP3 and $\alpha$-SMA $(n=4)$. D: Real-time RT-PCR $(n=3) .{ }^{*} P<0.05$ and ${ }^{* * *} P<0.01$ versus control; ${ }^{\dagger} P<0.05$ versus TGF- $\beta 1$ control. E: F-actin staining (phalloidin-Alexa594, red); nuclei were counterstained with DAPI (blue). HPMCs were transfected with $A Q P 3$ siRNA (si $A Q P 3$ ) or Ad- $A Q P 3$ for 24 hours and then either treated with $2 \mathrm{ng} / \mathrm{mL}$ TGF- $\beta 1$ or left untreated for 48 hours.

fiber projections. F-actin stress fiber formation was attenuated in cells treated with TGF- $\beta 1$ or siAQP3, and increased after transfection of Ad-AQP3 (Figure 5E).

\section{AQP3 Overexpression Induces Faster Migration of HPMCs}

To investigate whether AQP3 gene transfer influenced HPMC migration, HPMCs were infected with $100 \mathrm{MOls}$ of either a control adenovirus expressing Ad-GFP or an adenovirus expressing human AQP3. After Ad-AQP3 
A
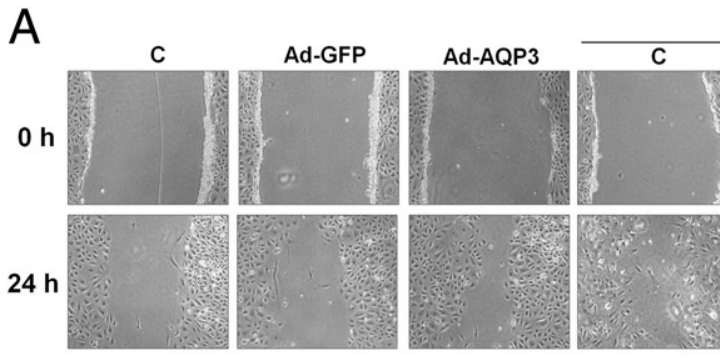

B

C

Ad-GFP

Ad-AQP3
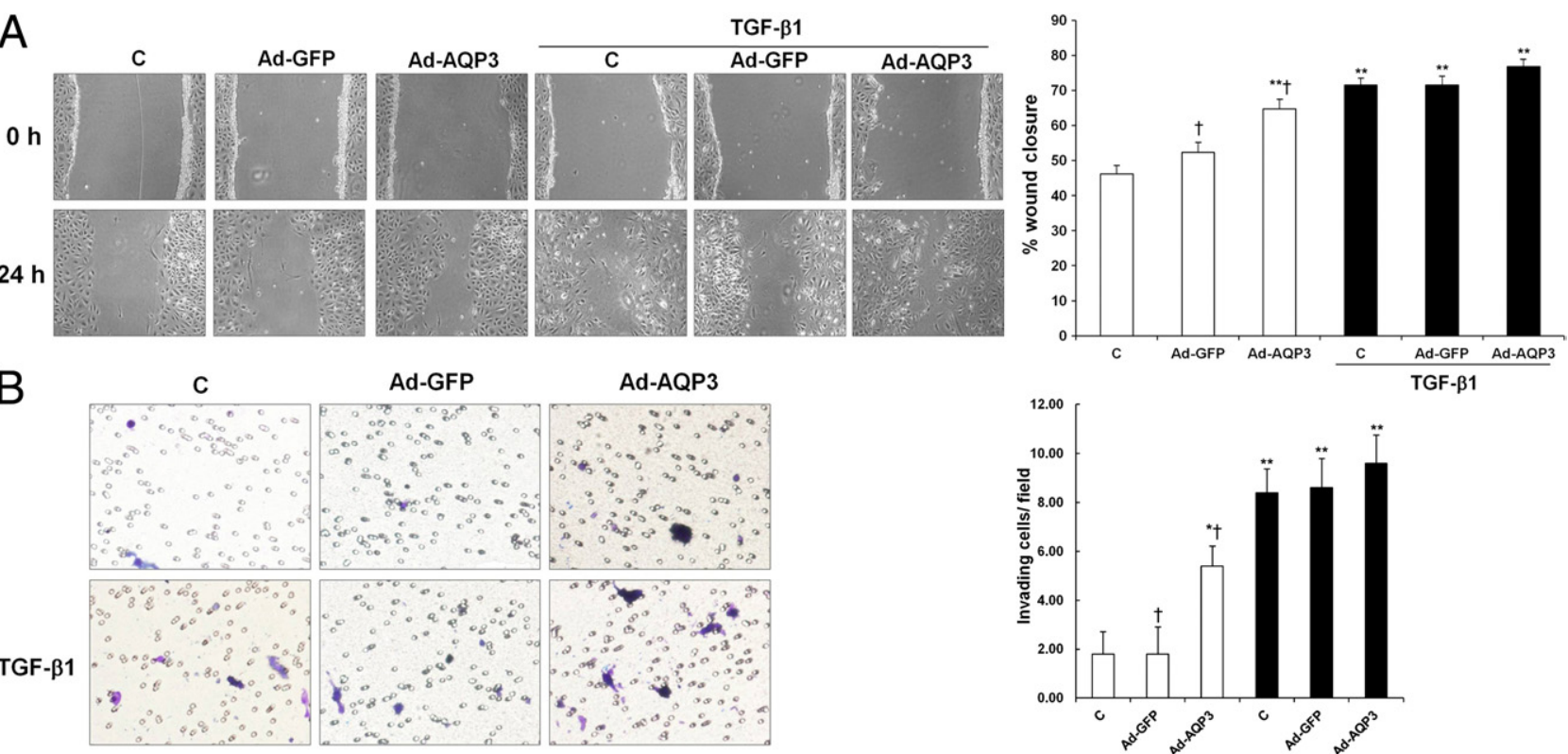

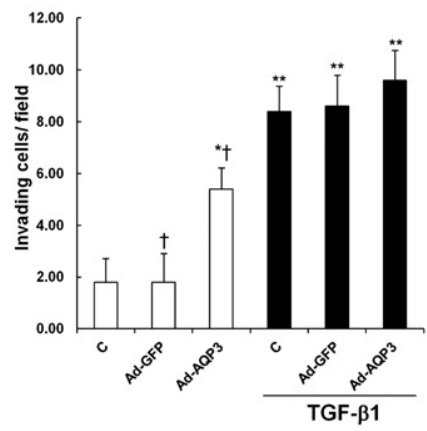

Figure 6. The effects of $A Q P 3$ overexpression on migration of HPMCs. A: In vitro wound-healing assay. HPMCs were infected with an adenovirus expressing human $A Q P 3$ (Ad-AQP3) or with one expressing GFP (Ad-GFP) as a negative control. Original magnification $\times 100$. B: Matrigel invasion assay. Phase micrograph of invading HPMCs. Invading cells were stained with $0.1 \%$ crystal violet solution. Bar graph represents the mean \pm SEM number of cells in 5 randomly selected microscopic fields. Original magnification $\times 100$. ${ }^{*} P<0.05$ and ${ }^{* * *} P<0.01$ versus control; ${ }^{\dagger} P<0.05$ versus TGF- $\beta 1$ control.

transfection, we observed faster migration in AQP3-overexpressing cells than in control cells but not in Ad-GFPtransfected cells (Figure 6, A and B). We could not find a significant difference between TGF- $\beta 1$ - or Ad-AQP3treated groups and the TGF- $\beta 1$-treated group on cell migration.

\section{Effect of MAPK Inhibitors on TGF- $\beta 1$-Induced AQP3 Expression}

Activation of the MAPK pathways after TGF- $\beta 1$ treatment of HPMCs for 1 hour was confirmed using Western blot analysis of $\mathrm{p}$-ERK1/2, p-JNK, and p-p38, respectively, using $\mathrm{p}$-protein-specific antibodies. Increased levels of $\mathrm{p}$-ERK1/2, p-JNK, and p-p38 were detected after 1 hour of TGF- $\beta 1$ treatment (Figure 7). TGF- $\beta 1$ induces a motile phenotype in HPMCs. The motile phenotype may be mediated, at least in part, by the MAPK pathway (Figure 7A).

HPMCs were pretreated with specific MAPK inhibitors (each at $20 \mu \mathrm{mol} / \mathrm{L}$ ) before treatment with TGF- $\beta 1$. The basal AQP3 levels in the presence of inhibitor were not significantly different from control. The treatment with an ERK inhibitor (PD98059) and a p38 kinase inhibitor (SB203580) significantly attenuated TGF- $\beta 1$-induced AQP3 expression in HPMCs. In contrast, treatment with a JNK inhibitor (SP600125) did not affect TGF- $\beta 1$-induced AQP3 expression. These results suggest that MAPK signaling is one of the pathways implicated in the TGF- $\beta 1-$ mediated regulation of AQP3 expression in HPMCs (Figure $7 \mathrm{~B})$.

\section{Discussion}

It is well known that TGF- $\beta$ is increased in PMCs exposed to PD solution ${ }^{12}$ and that AQP3 expression increases in the presence of glucose, an osmotic agent. ${ }^{9}$ It has also been established that TGF- $\beta$ and AQPs are involved in cell migration. ${ }^{24-26}$ However, the relationship between TGF- $\beta$ and AQP3 in PMCs and the role of AQP3 is unclear. In the present study, we found that TGF- $\beta$ and AQP3 expression was enhanced in the peritoneum after peritoneal injury in an in vivo PD model and that TGF- $\beta$ treated HPMCs exhibited increased AQP3 expression that facilitated PMC migration in an in vitro wound model.

TGF- $\beta 1$ is up-regulated in peritoneal injury and in peritoneal membrane fibrosis. The importance of TGF- $\beta$ in peritoneal fibrosis has been found in an in vivo rat model in which adenovirus-mediated overexpression of TGF- $\beta 1$ in the rat peritoneum resulted in peritoneal fibrosis, neoangiogenesis, and increased peritoneal permeability. ${ }^{27}$ TGF- $\beta 1$ is important in fibrosis and wound healing, which regulate many processes involved in tissue repair including production of extracellular matrix. ${ }^{28} \mathrm{TGF}-\beta$ is a potent profibrotic factor for PMC epithelial-to-mesenchymal transition, ${ }^{12}$ an early mechanism in peritoneal fibrosis and a process by which epithelial cell layers lose their polarity and cell-cell contacts and undergo dramatic remodeling of the cytoskeleton. ${ }^{29,30}$

In the present study, 8-week exposure to PD solution resulted in increased TGF- $\beta$ expression along with peritoneal fibrosis. The presence of dual $\alpha$-SMA- and cytokeratin-positive myofibroblasts was evidence of the epithelial-to-mesenchymal transition. Although the mesothelial cells are of mesodermal origin, they express epi- 
A

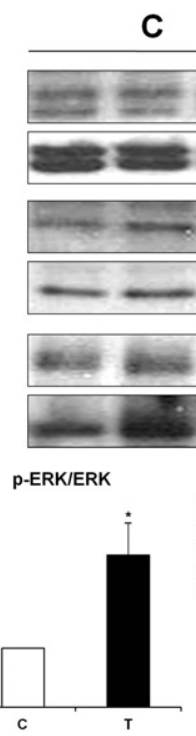

\section{(1)}

TGF- $\beta 1$



BEA ERK

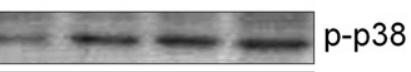

$-\cdots p 38$

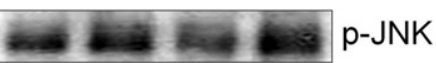

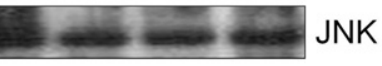

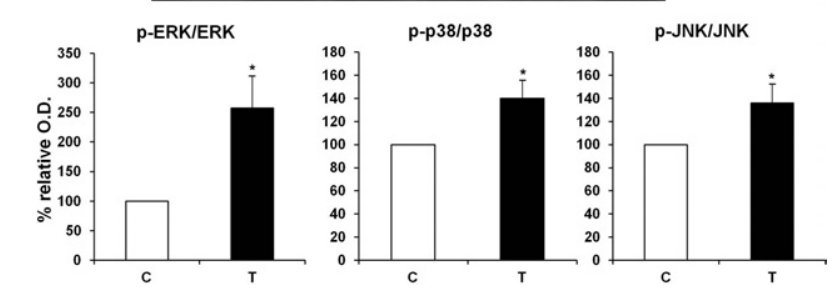

B
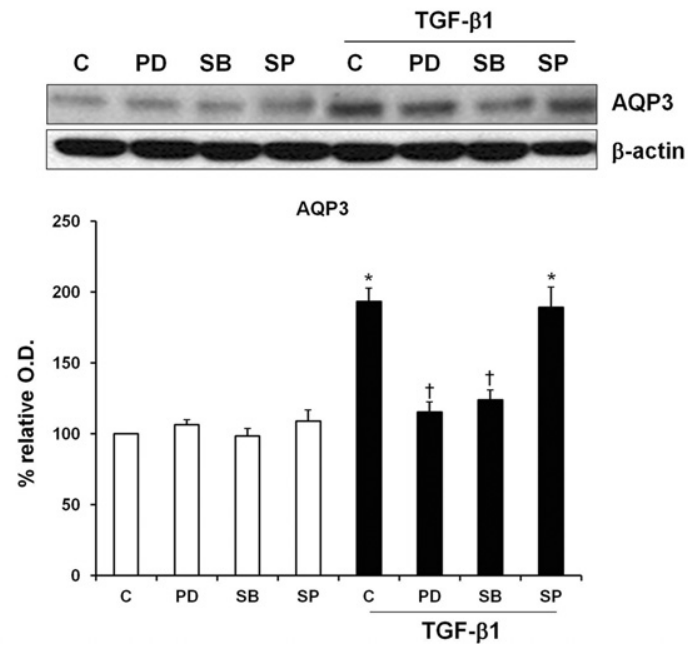

Figure 7. A: TGF- $\beta 1$-induced ERK, p38 MAPK, and JNK activation. HPMCs were treated with TGF- $\beta 1$ for 1 hour. The 3 lanes are representative of same-treated groups in 3 independent experiments. p-ERK1/2, p-JNK, and p-p38 levels increased after 1 hour of TGF- $\beta 1$ treatment. ${ }^{*} P<0.05$ versus control. B: Effect of MAPK inhibitors on TGF- $\beta 1$-induced $A Q P 3$ expression. HPMCs were treated for 1 hour with $20 \mu \mathrm{mol} / \mathrm{L}$ of either PD98059 (PD), SB203580 (SB), or SP600125 (SP), which are specific chemical inhibitors of MAPK/ERK kinase (MEK)1, p38, or JNK, respectively. After 1 hour, 2 ng/mL TGF- $\beta 1$ was added, and the cells were incubated for 48 hours $(n=4)$. Top panels, representative Western blot; bottom panels, relative increases in protein expression determined using densitometry $(n=4)$. ${ }^{*} P<0.05$ versus control; ${ }^{\dagger} P<0.05$ versus TGF- $\beta 1$ without MAPK inhibitor. C, control; T, TGF- $\beta 1-$ treated cell.

thelial cytokeratins. The expression of cytokeratin has been used for typical epithelial markers in epithelial-tomesenchymal transition of mesothelial cells during PD. ${ }^{22,30,31}$ Myofibroblasts are prominent components of fibrosis in many tissues including the kidney and peritoneum. These results are consistent with findings of our previous study. ${ }^{22}$

We used the chronic PD rat model to investigate the role of AQP3 in peritoneal injury. Long-term exposure to glucose-containing solution leads to peritoneal injury and, specifically, to structural changes and functional decline of the peritoneal membrane. ${ }^{11}$ Expression of AQPs in the peritoneum has been reported previously, with AQP1, one of the major AQPs found in the peritoneum, expressed in vascular endothelial cells. ${ }^{32}$ In addition, AQP1 knockout causes impaired water transport through the peritoneum. Apart from AQP1, reports of peritoneal expression of AQP3 or AQP4 have been inconsistent. Whereas AQP3 and AQP4 mRNA is expressed in the peritoneum, only AQP1 expression has been detected via immunocytochemistry. ${ }^{33}$ Lai et al ${ }^{8,9}$ have reported that $A Q P 1$ and $A Q P 3$ expression is remarkably low in mesothelial cells but can be induced by osmotic agents such as glucose and mannitol. Therefore, the role of AQP3 in the peritoneum is unclear. In the present study, we found increased AQP3 expression in the peritoneum after peritoneal injury.

A recent report described the role of AQP3 in cell migration during wound healing in endothelial cell cultures derived from wild-type and Aqp1-null mice. ${ }^{25}$ In the eye, AQP3 expression increases the migration and proliferation of corneal epithelial cells after corneal wounding. ${ }^{34}$ Expression of AQP3 also increases keratinocyte migration and proliferation, and AQP3-deficient mice have impaired wound healing. ${ }^{35}$ AQP3 knockdown by siRNA reduces epidermal growth factor-induced skin fibroblast migration. ${ }^{36}$ However, although AQP3 has an important role in wound repair and cell migration, there is little information about the regulation of AQP3 gene expression in the peritoneum and in PMCs. In the present study, AQP3 mediated HPMC migration.

Considering the role of TGF- $\beta$ in wound healing and the role of AQP3 in cell migration, along with evidence of increased TGF- $\beta$ and AQP3 in a peritoneal injury model, one might hypothesize that TGF- $\beta$ contributes to AQP3 regulation in some way. To date, however, no studies have addressed this hypothesis. Thus, to investigate the relationship between AQP3 and TGF- $\beta 1$ in HPMCs, we incubated isolated HPMCs in medium containing TGF$\beta 1$. The architecture of mesothelial cells converted to fibroblast-like features after TGF- $\beta 1$ treatment. This result is in accordance with the results of a previous study that reported conversion of cultured mesothelial cells to myofibroblasts after stimulation with TGF- $\beta 1 .{ }^{37}$ We also investigated the relationship between mesothelial cell fibrosis and AQP3 expression in HPMCs. Although immunoblotting showed that the AQP3 protein was weakly expressed in HPMCs, AQP3 transcripts and protein were increased by TGF- $\beta 1$ in a time- and dose-dependent manner. In addition, the level of $\alpha$-SMA increased after TGF- $\beta 1$ treatment. Because the presence of $\alpha$-SMA is a phenotypic hallmark of myofibroblasts, ${ }^{38}$ this finding indicates that up-regulation of AQP3 after TGF- $\beta 1$ treatment of HPMCs stimulates transdifferentiation to myofibroblasts. To our knowledge, there have been no previous reports of the effect of TGF- $\beta 1$ on AQP3 expression.

To examine the role of AQP3 in TGF- $\beta$ 1-treated HPMCs, we performed an RNAi experiment to knock down AQP3 expression. AQP3-specific siRNAs attenuated TGF- $\beta 1$-induced $\alpha$-SMA transcript and protein expression, and the cobblestone-like appearance of cells treated with TGF- $\beta 1$ or siAQP3 remained unchanged. In immunofluorescence studies, TGF- $\beta 1$-treated cells have more robust stress fibers and higher $\alpha$-SMA expression 
than control cells do. In the present study, phalloidin staining revealed that TGF- $\beta 1$ stimulated reorganization of the actin cytoskeleton from an apical ring-like structure to stress fibers that are typical of fibroblasts. SiAQP3 treatment attenuated the TGF- $\beta 1$-induced formation of stress fibers, and $\alpha$-SMA expression increased after transfection of Ad-AQP3. These results demonstrated that knockdown of AQP3 induces morphologic changes and reduces stress fiber formation in HPMCs.

In the migration assay, there was slower HPMC migration after siAQP3 or TGF- $\beta 1$ treatment than with TGF- $\beta 1$ treatment alone. To verify whether the wound closure in HPMCs is due to TGF- $\beta 1$-induced proliferation or TGF$\beta 1$-induced migration, we performed BrdU incorporation assays. Although some studies reported that TGF- $\beta 1$ stimulates proliferation of fibroblasts and smooth muscle cells, ${ }^{39}$ it inhibits proliferation of epithelial cells, human colon carcinoma cells, and mesothelioma cells. ${ }^{40-42}$ The effects of TGF- $\beta 1$ on proliferation may vary, even within the same cell type, with different TGF- $\beta 1$ concentrations. ${ }^{43}$ In the present study, BrdU incorporation in HPMCs was inhibited by TGF- $\beta 1$ and was not changed by siAQP3. Therefore, proliferation is not involved in the migration of HPMCs induced by TGF- $\beta 1$. Together, these results show that SiAQP3 can block TGF- $\beta 1$-induced migration.

After Ad-AQP3 transfection, we observed faster migration in the AQP3-overexpressing cells than in the control cells. These results suggest that AQP3 might accelerate HPMC migration. However, we could not find a significant difference between the TGF- $\beta 1$ - or Ad-AQP3- treated groups and the TGF- $\beta 1$-treated group on cell migration despite greater AQP3 protein expression.

Our finding that TGF- $\beta 1$-induced AQP3 mediates HPMC migration is consistent with the recent discovery that AQP3 knockdown reduces the speed of skin fibroblast migration. ${ }^{35}$ Saadoun et al ${ }^{6}$ hypothesized that fibroblast migration involves water flux across the plasma membrane, which causes localized swelling of lamellipodia and leads to cell migration. Cell migration is required for many biological processes, and fibroblast migration is mediated by cytoskeletal reorganization. ${ }^{44}$ Boland et al ${ }^{24}$ reported that TGF- $\beta 1$ promotes actin cytoskeleton reorganization and elicits a migratory phenotype in epithelial tracheal cells and, furthermore, that the cell became elongated and developed lamellipodia in response to TGF- $\beta 1$. Lamellipodia are flat sheetlike protrusions formed at the leading edge of migrating cells and have a major role in driving cell migration by attaching to the substrate and generating force to pull the cell body forward. ${ }^{45}$ In the present study, TGF- $\beta 1$ induced an elongated cell, increased stress fiber formation, and increased cell migration. To investigate the molecular mechanism underlying TGF- $\beta 1$-induced migration, we performed a MAPK inhibitor study. We found that both PD98059 (an ERK inhibitor) and SB203580 (a p38 inhibitor) attenuated the TGF- $\beta 1$-induced increase in AQP3 expression. In contrast, SP600125 (a JNK inhibitor) did not affect TGF- $\beta 1$-induced AQP3 expression. TGF- $\beta 1$ mediates the MAPK signaling pathway, ${ }^{46}$ and Hara-Chikuma and Verkman ${ }^{35}$ reported that mitogen-induced cell proliferation was impaired in AQP3-deficient keratinocytes, which also had reduced p38 MAPK activity. It thus seems likely that the decrease in AQP3 expression induced by TGF- $\beta 1$ is mediated by MAPKs. Similar MAPKdependent increases in AQP3 expression were reported by Horie et al. ${ }^{47}$ In their report, the decrease in AQP3 expression caused by TNF- $\alpha$ was attenuated by SB203580 and PD98059. Results of 2 of these studies ${ }^{35,47}$ indicate the importance of MAPKs in regulating AQP3 gene transcription. The present study reports for the first time that TGF- $\beta 1$ increases AQP3 expression via p38 and ERK activation.

The present study provides novel evidence that TGF- $\beta 1$ induces AQP3 expression in HPMCs, that overexpression of AQP3 may stimulate reorganization of stress fibers, and that AQP3 facilitates the migration of HPMCs. Together, these observations suggest that AQP3 may be important in wound healing after peritoneal injury. Modulation of AQP3 production might be useful as a novel therapeutic strategy for controlling peritoneal fibrosis and speeding wound healing.

\section{References}

1. Agre $P$, King LS, Yasui M, Guggino WB, Ottersen OP, Fujiyoshi $Y$, Engel A, Nielsen S: Aquaporin water channels: from atomic structure to clinical medicine. J Physiol 2002, 542:3-16

2. Morishita $Y$, Matsuzaki T, Hara-chikuma M, Andoo A, Shimono M, Matsuki A, Kobayashi K, Ikeda M, Yamamoto T, Verkman A, Kusano E, Ookawara S, Takata K, Sasaki S, Ishibashi K: Disruption of aquaporin-11 produces polycystic kidneys following vacuolization of the proximal tubule. Mol Cell Biol 2005, 25:7770-7779

3. Itoh T, Rai T, Kuwahara M, Ko SB, Uchida S, Sasaki S, Ishibashi K: Identification of a novel aquaporin, AQP12, expressed in pancreatic acinar cells. Biochem Biophys Res Commun 2005, 330:832-838

4. Mobasheri A, Wray S, Marples D: Distribution of AQP2 and AQP3 water channels in human tissue microarrays. J Mol Histol 2005, 36: $1-14$

5. Saadoun S, Papadopoulos MC, Hara-Chikuma M, Verkman AS: Impairment of angiogenesis and cell migration by targeted aquaporin-1 gene disruption. Nature 2005, 434:786-792

6. Saadoun S, Papadopoulos MC, Watanabe H, Yan D, Manley GT, Verkman AS: Involvement of aquaporin-4 in astroglial cell migration and glial scar formation. J Cell Sci 2005, 118:5691-5698

7. Hara-Chikuma M, Verkman AS: Aquaporin-1 facilitates epithelial cell migration in kidney proximal tubule. J Am Soc Nephrol 2006, 17: $39-45$

8. Lai KN, Li FK, Lan HY, Tang S, Tsang AW, Chan DT, Leung JC: Expression of aquaporin-1 in human peritoneal mesothelial cells and its upregulation by glucose in vitro. J Am Soc Nephrol 2001, 12:10361045

9. Lai KN, Leung JC, Chan LY, Tang S, Li FK, Lui SL, Chan TM: Expression of aquaporin-3 in human peritoneal mesothelial cells and its up-regulation by glucose in vitro. Kidney Int 2002, 62:1431-1439

10. Chegini N: TGF-beta system: the principal profibrotic mediator of peritoneal adhesion formation. Semin Reprod Med 2008, 26:298-312

11. Selgas R, Bajo A, Jiménez-Heffernan JA, Sánchez-Tomero JA, Del Peso G, Aguilera A, López-Cabrera M: Epithelial-to-mesenchymal transition of the mesothelial cell: its role in the response of the peritoneum to dialysis. Nephrol Dial Transplant 2006, 21(Suppl 2):ii2-ii7

12. Hirahara I, Kusano E, Yanagiba S, Miyata Y, Ando Y, Muto S, Asano $Y$ : Peritoneal injury by methylglyoxal in peritoneal dialysis. Perit Dial Int 2006, 26:380-392

13. Yung S, Li FK, Chan TM: Peritoneal mesothelial cell culture and biology. Perit Dial Int 2006, 26:162-173

14. Williams JD, Craig KJ, Topley N, Von Ruhland C, Fallon M, Newman GR, Mackenzie RK, Williams GT; Peritoneal Biopsy Study Group: Morphologic changes in the peritoneal membrane of patients with renal disease. J Am Soc Nephrol 2002, 13:470-479 
15. Arora PD, McCulloch CA: Dependence of collagen remodelling on alpha-smooth muscle actin expression by fibroblasts. J Cell Physiol 1994, 159:161-175

16. Desmoulière A, Chaponnier C, Gabbiani G: Tissue repair, contraction, and the myofibroblast. Wound Repair Regen 2005, 13:7-12

17. Desmoulière A, Darby IA, Gabbiani G: Normal and pathologic soft tissue remodeling: role of the myofibroblast, with specific emphasis on liver and kidney fibrosis. Lab Invest 2003, 83:1689-1707

18. Thannickal VJ, Toews GB, White ES, Lynch JP III, Martinez FJ: Mechanisms of pulmonary fibrosis. Annu Rev Med 2004, 55:395-417

19. Bottinger EP, Bitzer M: TGF- $\beta$ signaling in renal disease. J Am Soc Nephrol 2002, 13:2600-2610

20. Margetts PJ, Oh KH, Kolb M: Transforming growth factor-beta: importance in long-term peritoneal membrane changes. Perit Dial Int 2005, 25(Suppl 3):S15-S17

21. Cutroneo KR: TGF-beta-induced fibrosis and SMAD signaling: oligo decoys as natural therapeutics for inhibition of tissue fibrosis and scarring. Wound Repair Regen 2007, 15(Suppl 1):S54-S60

22. Yu MA, Shin KS, Kim JH, Kim YI, Chung SS, Park SH, Kim YL, Kang $\mathrm{DH}$ : HGF and BMP-7 ameliorate high glucose-induced epithelial-tomesenchymal transition of peritoneal mesothelium. J Am Soc Nephrol 2009, 20:567-581

23. Oh EJ, Ryu HM, Choi SY, Yook JM, Kim CD, Park SH, Chung HY, Kim IS, Yu MA, Kang DH, Kim YL: Impact of low glucose degradation product bicarbonate/lactate-buffered dialysis solution on the epithelial-mesenchymal transition of peritoneum. Am J Nephrol 2010, 31: 58-67

24. Boland S, Boisvieux-Ulrich E, Houcine O, Baeza-Squiban A, Pouchelet M, Schoëvaërt D, Marano F: TGF beta 1 promotes actin cytoskeleton reorganization and migratory phenotype in epithelial tracheal cells in primary culture. J Cell Sci 1996, 109(Pt 9):2207-2219

25. Ni J, Verbavatz JM, Rippe A, Boisdé I, Moulin P, Rippe B, Verkman AS, Devuyst O: Aquaporin-1 plays an essential role in water permeability and ultrafiltration during peritoneal dialysis. Kidney Int 2006 69:1518-1525

26. Verkman AS: Aquaporins in clinical medicine. Annu Rev Med 2012 63:303-316

27. Margetts PJ, Kolb M, Galt T, Hoff CM, Shockley TR, Gauldie J: Gene transfer of transforming growth factor-beta1 to the rat peritoneum: effects on membrane function. J Am Soc Nephrol 2001, 12:20292039

28. Thiery JP, Sleeman JP: Complex networks orchestrate epithelialmesenchymal transitions. Nat Rev Mol Cell Biol 2006, 7:131-142

29. Kalluri R, Neilson EG: Epithelial-mesenchymal transition and its implications for fibrosis. J Clin Invest 2003, 112:1776-1784

30. YÁñez-Mó M, Lara-Pezzi E, Selgas R, Ramírez-Huesca M, Domínguez-Jiménez $C$, Jiménez-Heffernan JA, Aguilera A, SánchezTomero JA, Bajo MA, Alvarez V, Castro MA, del Peso G, Cirujeda A, Gamallo C, Sánchez-Madrid F, López-Cabrera M: Peritoneal dialysis and epithelial-to-mesenchymal transition of mesothelial cells [published correction appears in N Engl J Med 2005, 353:2827]. N Engl J Med 2003, 348:403-413

31. Margetts PJ, Bonniaud P, Liu L, Hoff CM, Holmes CJ, West-Mays JA, Kelly MM: Transient overexpression of TGF-\{beta\} 1 induces epithelial mesenchymal transition in the rodent peritoneum. J Am Soc Nephrol 2005, 16:425-436
32. Devuyst O, Nielsen S, Cosyns JP, Smith BL, Agre P, Squifflet JP, Pouthier D, Goffin E: Aquaporin-1 and endothelial nitric oxide synthase expression in capillary endothelia of human peritoneum. Am J Physiol 1998, 275(1, Pt 2): H234-H242

33. Akiba T, Ota T, Fushimi K, Tamura H, Hata T, Sasaki S, Marumo F: Water channel AQP1, 3, and 4 in the human peritoneum and peritoneal dialysate. Adv Perit Dial 1997, 13:3-6

34. Levin MH, Verkman AS: Aquaporin-3-dependent cell migration and proliferation during corneal re-epithelialization. Invest Ophthalmol Vis Sci 2006, 47:4365-4372

35. Hara-Chikuma M, Verkman AS: Aquaporin-3 facilitates epidermal cell migration and proliferation during wound healing. J Mol Med (Berl) 2008, 96:221-231

36. Cao C, Sun Y, Healey S, Bi Z, Hu G, Wan S, Kouttab N, Chu W, Wan Y: EGFR-mediated expression of aquaporin-3 is involved in human skin fibroblast migration. Biochem J 2006, 400:225-234

37. Yang AH, Chen JY, Lin JK: Myofibroblastic conversion of mesothelia cells. Kidney Int 2003, 63:1530-1539

38. Hinz B, Dugina V, Ballestrem C, Wehrle-Haller B, Chaponnier C: Alpha-smooth muscle actin is crucial for focal adhesion maturation in myofibroblasts. Mol Biol Cell 2003, 14:2508-2519

39. Chen G, Khalil N: TGF-beta1 increases proliferation of airway smooth muscle cells by phosphorylation of map kinases. Respir Res 2006, $7: 2$

40. Hartsough MT, Mulder KM: Transforming growth factor beta activation of p44mapk in proliferating cultures of epithelial cells. J Biol Chem 1995, 270:7117-7124

41. Wu SP, Theodorescu D, Kerbel RS, Willson JK, Mulder KM, Humphrey LE, Brattain MG: TGF-beta 1 is an autocrine-negative growth regulator of human colon carcinoma FET cells in vivo as revealed by transfection of an antisense expression vector. J Cell Biol 1992 116:187-196

42. Zhong J, Gencay MM, Bubendorf L, Burgess JK, Parson H, Robinson BW, Tamm M, Black JL, Roth M: ERK1/2 and p38 MAP kinase control MMP-2, MT1-MMP, and TIMP action and affect cell migration: a comparison between mesothelioma and mesothelial cells. J Cell Physiol 2006, 207:540-552

43. Battegay EJ, Raines EW, Seifert RA, Bowen-Pope DF, Ross R: TGFbeta induces bimodal proliferation of connective tissue cells via complex control of an autocrine PDGF loop. Cell 1990, 63:515-524

44. Acharya PS, Majumdar S, Jacob M, Hayden J, Mrass P, Weninger W, Assoian RK, Puré E: Fibroblast migration is mediated by CD44dependent TGF beta activation. J Cell Sci 2008, 121(Pt 9):1393-1402

45. Yamaguchi $\mathrm{H}$, Condeelis $\mathrm{J}$ : Regulation of the actin cytoskeleton in cancer cell migration and invasion. Biochim Biophys Acta 2007. 1773:642-652

46. Tsukada S, Westwick JK, Ikejima K, Sato N, Rippe RA: SMAD and p38 MAPK signaling pathways independently regulate alpha1(I) collagen gene expression in unstimulated and transforming growth factor-beta-stimulated hepatic stellate cells. J Biol Chem 2005, 280: 10055-10064

47. Horie I, Maeda M, Yokoyama S, Hisatsune A, Katsuki H, Miyata T, Isohama $Y$ : Tumor necrosis factor-alpha decreases aquaporin-3 expression in DJM-1 keratinocytes. Biochem Biophys Res Commun 2009, 387:564-568 